\title{
Effects of Noise and Absorption on High Frequency Measurements of Acoustic-Backscatter from Fish
}

\author{
Masahiko Furusawa \\ Tokyo University of Marine Science and Technology, 4-5-7 Kounan, Minato, Tokyo 108-8477, Japan \\ Correspondence should be addressed to Masahiko Furusawa; frsw@fine.ocn.ne.jp
}

Received 7 June 2015; Accepted 12 October 2015

Academic Editor: Renzo Perissinotto

Copyright (C) 2015 Masahiko Furusawa. This is an open access article distributed under the Creative Commons Attribution License, which permits unrestricted use, distribution, and reproduction in any medium, provided the original work is properly cited.

Quantitative echosounders operating at multiple frequencies (e.g., 18, 38, 70, 120, 200, 333, and 710 kHz) are often used to observe fish and zooplankton and identify their species. At frequencies above $100 \mathrm{kHz}$, the absorption attenuation increases rapidly and decreases the signal-to-noise ratio (SNR). Also, incomplete compensation for the attenuation may result in measurement error. This paper addresses the effects of the attenuation and noise on high frequency measurements of acoustic backscatter from fish. It is shown that measurements of a fish with target strength of $-40 \mathrm{~dB}$ at $200 \mathrm{~m}$ depth are limited by SNR to frequencies up to about $100 \mathrm{kHz}$. Above $100 \mathrm{kHz}$, absorption coefficients must be matched to local environmental conditions.

\section{Introduction}

Quantitative echosounders (QES) or scientific echosounders have evolved for routine use in acoustic surveys of fisheries resources [1]. Traditionally, QES operate at $38 \mathrm{kHz}$ with low attenuation, a high signal-to-noise ratio (SNR), and small measurement errors [2]. Recently, however, QES are often operated at multiple frequencies including higher frequencies, for example, 18, 38, 70, 120, 200, 333, and $400 \mathrm{kHz}$ [3]; 70, $120,200,333$, and $710 \mathrm{kHz}$ [4]; and 125, 200, 455, and $770 \mathrm{kHz}$ [5], to classify and study fish and zooplankton. Measurements at the higher frequencies, particularly those above $100 \mathrm{kHz}$, are affected by increasingly high and uncertain absorption attenuation and therefore increasingly low SNR and measurement accuracy. This paper highlights some considerations when measuring with high frequencies, estimates associated errors, and proposes mitigation measures to obtain precise and accurate data.

The frequency dependence of backscatter provides useful information for fish species identification $[6,7]$. To evaluate the accuracy that can be achieved by multifrequency QES, the SNR is quantified, considering the limitation of transmit power due to nonlinear phenomenon, and acoustic noise from various sources. Then, effective measurement ranges are identified for various frequencies using a modified diagram of QES performance [2]. Also, error from absorption attenuation at high frequencies is quantified and discussed.

\section{Materials and Methods}

2.1. Noise. There are several sources of acoustic noise received by a QES (Figure 1), such as rain, wind-induced wave, snapping shrimp, self-vessel, and heat (thermal noise). Similar to [2], the noise power spectral level of the vessel self-noise is modeled here as

$$
N_{V}=\frac{N_{V 0}}{f^{2}}
$$

where $N_{V 0}$ is the noise power spectral level for frequency $f$ projected to $1 \mathrm{~Hz}$. In the case of the upper vessel self-noise [8] in Figure $1, N V_{0}=10 \log N_{V 0}=155 \mathrm{~dB}$ re $1 \mu \mathrm{Pa}^{2} \mathrm{~Hz}$. (Throughout this paper, the MKS system of units is kept in equations, but actual values are expressed sometimes in convenient units as in this case.) The lower vessel self-noise in Figure 1 was obtained by fitting (1) to the noise spectral level data for a noise-reduced vessel [9], and the value of $N V_{0}$ is $142 \mathrm{~dB}$. The thermal noise spectrum was deduced from the formula in [10] and expressed as

$$
N_{T}=N_{T 0} f^{2},
$$




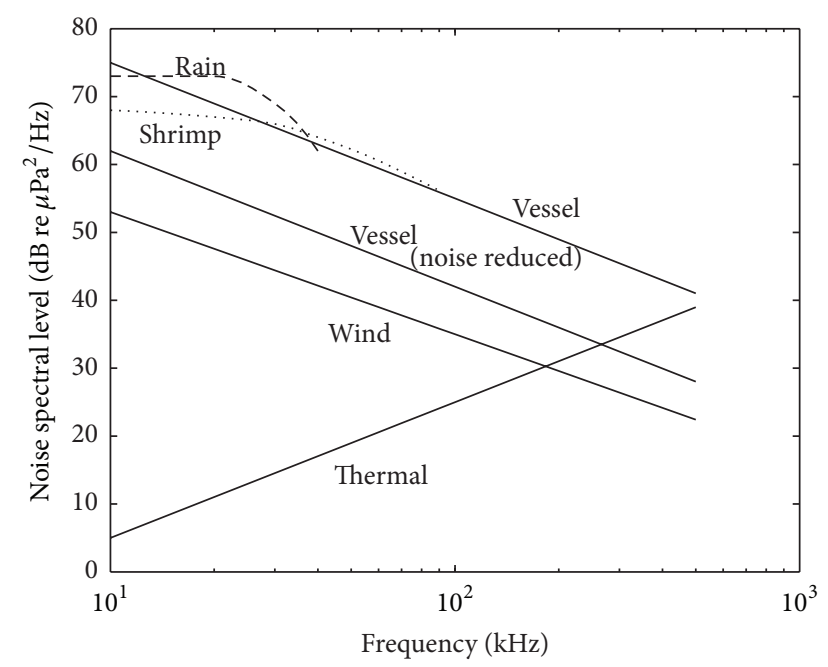

FIGURE 1: Noise power spectrum level ( $\mathrm{dB}$ re $1 \mu \mathrm{Pa}^{2} / \mathrm{Hz}$ ) relevant to acoustic surveys of fish resources. Heavy rain $(100 \mathrm{~mm} / \mathrm{h})$ noise [11], snapping shrimp noise [12], vessel self-noise of RV "Hokko-maru" (220-tonne steel ship at a speed of 11 knots) [8], vessel self-noise of RV "Soyo-maru" (892-tonne noise-reduced ship at a speed of 10 knots) [9], wind-induced noise at rough sea (sea state 6) [13], and sea thermal noise (water temperature $10^{\circ} \mathrm{C}$ ) [10] are shown.

where $10 \log N_{T 0}=-75 \mathrm{~dB}$ re $1 \mu \mathrm{Pa}^{2} \mathrm{~Hz}^{-3}$. Although noise from rain or shrimp may occasionally dominate the noise level for short periods or small regions, noise below $100 \mathrm{kHz}$ is generally dominated by the vessel self-noise. Electrical noise in the QES transducer and receiver may be significant at higher frequencies and will be considered later.

2.2. Signal-to-Noise Ratio. The echo level of a single scatterer is, in general, smaller than the echo level of a multiple scatterer, and therefore the SNR for single scatterer must be considered primarily in the design and utilization of QES. Furthermore, the SNR for the average value of volume backscattering coefficients $\left(s_{V}\right)$ as the output of echo integration decreases especially for single scatterers for the following reason. The $s_{V}$ are obtained for each of the multiple scatterers, single scatterers, and even noise in each minimal processing cell called a pixel which is the region enclosed by a ping period and a sampling period along the depth axis [14]. The output of echo integration is the integration of the pixel $s_{V}$ over an area of a lager integration cell. Let the pixel $s_{V}$ of the echoes be $s_{V, E}$, let the pixel $s_{V}$ of the noise be $s_{V, N}$, let the area which the echoes occupy in the cell be $A_{E}$, and let the area of the cell be $A_{C}$; then we have the cell or average $s_{V}$ :

$$
s_{V, C}=\frac{\sum s_{V, E} A_{E}+s_{V, N} A_{C}}{A_{C}} .
$$

Assuming, for simplicity, that the backscatter within $A_{C}$ is homogeneous, the SNR for $s_{V, C}$ is

$$
R_{C}=\frac{s_{V, E} \sum A_{E}}{s_{V, N} A_{C}}=R \frac{\sum A_{E}}{A_{C}}
$$

where $R$ is the SNR for the echo power. Therefore, the SNR of the cell $s_{V}$ (i.e., $R_{C}$ ) is proportional to the area occupied by the scatterers divided by the cell area. Because $s_{V, E}$ and $A_{E}$ are generally smaller for single versus multiple scatterers, the worst case $R_{C}$ is probably that for single scatterers. From the above reasoning, the signal for the basis of the SNR should be single scatterer echoes.

In terms of pressure, the SNR for a single scatterer is

$$
R_{F}=\frac{P_{F}^{2}}{P_{N}^{2}},
$$

where $P_{F}$ is the echo pressure from a scatterer and $P_{N}$ is the noise pressure. This $R_{F}$ is expressed by several variables as described in [2], but the noise expression is slightly changed as (1) and a transmit power per unit transducer area is changed from a value obtained by the cavitation threshold to a value determined to avoid the nonlinear effect of transmission $[15,16]$. From the examples of the frequency, transmit electric power, and beam width of QES shown in [3], we adopt $2.5 \mathrm{~W} / \mathrm{cm}^{2}$ as the electric power density for all frequencies examined.

The transmitted pressure $\left(P_{0}\right)$ squared is

$$
P_{0}^{2}=\frac{\eta w \pi a^{2} D_{I}}{4 \pi r_{0}^{2}} \rho c=\frac{\rho c a^{2} \eta w D_{I}}{4 r_{0}^{2}},
$$

where $w$ is the electric power density determined above, $\eta$ is the electroacoustic efficiency, $a$ is the transducer radius, $r_{0}$ is the standard range $(1 \mathrm{~m}), \rho$ is the density of seawater, $c$ is the sound speed in seawater, and $D_{I}$ is the directivity index shown approximately by [11]

$$
D_{I}=\left(\frac{2 \pi f}{c} a\right)^{2} .
$$

The single echo pressure $\left(P_{F}\right)$ squared is

$$
P_{F}^{2}=P_{0}^{2} D^{4} \frac{r_{0}^{2}}{r^{4} 10^{0.2 \alpha(f) r}} \sigma_{\mathrm{bs}}
$$

where $D$ is the directivity coefficient, $r$ is the range between the transducer and fish, $\alpha(f)\left(\mathrm{dB} \mathrm{m}^{-1}\right)$ is the frequency dependent absorption coefficient, and $\sigma_{\mathrm{bs}}$ is the backscattering cross sectional area of the scatterer. The target strength is expressed as TS $=10 \log \left(\sigma_{\mathrm{bs}} / r_{0}{ }^{2}\right)$. Using (1) and considering $D_{I}$ and the bandwidth of the receiving system $(\Delta f)$, the noise pressure $\left(P_{N}\right)$ squared is

$$
P_{N}^{2}=\frac{N_{V 0} \Delta f}{f^{2} D_{I}} .
$$

Substituting (6)-(9) into (5), we have the expression of the SNR:

$$
R_{F}=\frac{4 \pi^{4} \rho}{c^{3}} \cdot \frac{\eta w D^{4} \sigma_{\mathrm{bs}}}{N_{V 0} \Delta f} \cdot \frac{a^{6} f^{6}}{r^{4} 10^{0.2 \alpha(f) r}} .
$$

The first factor of (10) is nearly constant, the second factor may be assumed to be a constant and the effect of a value 
change can be easily seen by a shift of the SNR scale (from this reason, we call the parameters in the second factor "adjustable parameters"), and the last factor greatly changes the SNR. A transducer radius is approximately related to the $-3 \mathrm{~dB}$ beam width $\Theta$ in radian by

$$
a \cong \frac{0.51 c}{\Theta f}
$$

Substituting this into (10) gives another expression of the SNR:

$$
R_{F}=4 \times 0.51^{6} \pi^{4} c^{3} \rho \cdot \frac{\eta w D^{4} \sigma_{\mathrm{bs}}}{N_{V 0} \Delta f} \cdot \frac{1}{\Theta^{6} r^{4} 10^{0.2 \alpha(f) r}} .
$$

In this expression, the factor $f^{6}$ in (10) disappears and only the absorption attenuation remains as a frequency dependent factor.

Since the SNR changes dramatically with $a$ or $\Theta, f$, and $r$, it should be an effective way to show the SNR as a function of $f$ with parameters $r, a$, and $\Theta$ as in [2]; we call the resultant graph the universal diagram of echosounder performance. The following values are used for the nearly constant and adjustable parameters:

$$
\begin{aligned}
c & =1500 \mathrm{~m} / \mathrm{s}, \\
\rho & =1025 \mathrm{~kg} / \mathrm{m}^{3}, \\
\eta & =0.6[3], \\
w & =2.5 \mathrm{~W} / \mathrm{cm}^{2}[3], \\
D & =1, \\
\mathrm{TS} & =-40 \mathrm{~dB}, \\
N V_{0} & =155 \mathrm{~dB} \text { re } 1 \mu \mathrm{Pa}^{2} \mathrm{~Hz}, \\
\Delta f & =2.5 \mathrm{kHz} .
\end{aligned}
$$

If our objects are only multiple or school echoes as in species identification using school echoes, we may consider the SNR for the multiple echo. The multiple echo from a fish school is expressed as

$$
P_{M}^{2}=P_{0}^{2} \cdot \frac{r_{0}^{2}}{r^{4} 10^{0.2 \alpha(f) r}} \cdot \frac{c \tau}{2} \Psi r^{2} \cdot n \sigma_{\mathrm{bs}},
$$

where $P_{M}$ is the pressure of multiple echo, $\tau$ is the pulse duration, $\Psi$ is the equivalent beam angle in steradians, and $n$ is the distribution density of fish or any animals in $\mathrm{m}^{-3}$. The second factor is the propagation attenuation, the third factor is the scattering volume and the $r^{2}$ factor included cancels the one-way spreading attenuation in the second factor, and the fourth factor is the volume backscattering coefficient $s_{V}$. The $\Psi$ can be approximated by [11] (coefficient is rounded):

$$
\Psi \cong \frac{6 c^{2}}{4 \pi^{2} f^{2} a^{2}} .
$$

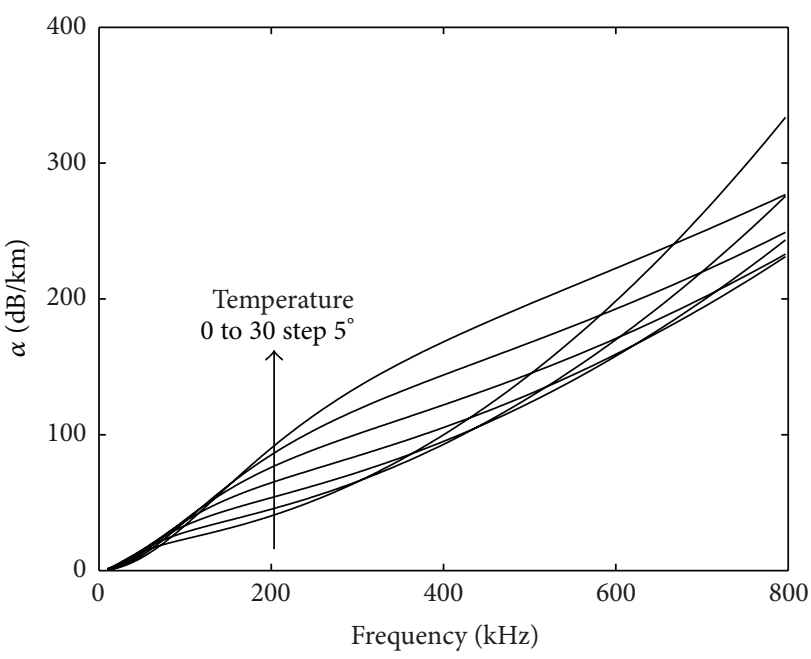

FIGURE 2: Absorption coefficient by Francois and Garrison's equations $[17,18]$ as a function of frequency with parameter of water temperature for constant values of the salinity $35 \mathrm{psu}$, depth $100 \mathrm{~m}$, sound speed $1500 \mathrm{~m} / \mathrm{s}$, and $\mathrm{pH} 8$. Note the inversion of temperature dependence around 70 and $500 \mathrm{kHz}$.

Similarly as in the single echo case, the SNR for the multiple echo is derived as

$$
\begin{aligned}
R_{M} & =\frac{P_{M}^{2}}{P_{N}{ }^{2}}=3 \pi^{2} \rho \cdot \frac{\eta w \tau n \sigma_{\mathrm{bs}}}{N_{V 0} \Delta f} \cdot \frac{a^{4} f^{4}}{r^{2} 10^{0.2 \alpha(f) r}} \\
& =3 \times 0.51^{4} \pi^{2} c^{4} \rho \cdot \frac{\eta w \tau n \sigma_{\mathrm{bs}}}{N_{V 0} \Delta f} \cdot \frac{1}{\Theta^{4} r^{2} 10^{0.2 \alpha(f) r}},
\end{aligned}
$$

where the first factor may be considered as a constant, the second adjustable parameters, and the third important parameters or variables. The adjustable parameter values other than $D$ are assumed to be the same as in (13) and the two parameter values added are

$$
\begin{aligned}
\tau & =1 \mathrm{~ms} \\
n & =0.1 \mathrm{~m}^{-3}\left(S_{V}=10 \log s_{V}=-50 \mathrm{~dB}\right. \text { with TS } \\
& =-40 \mathrm{~dB}) .
\end{aligned}
$$

2.3. Absorption Attenuation. The absorption coefficient $\alpha$ is a function of water temperature, salinity, depth, and $\mathrm{pH}[17$, 18]. The temperature changes the absorption coefficient most among these parameters, and the temperature itself changes largely in time and space. For the present purpose, therefore, it is sufficient to consider the effect of the frequency and temperature (Figure 2).

Seasonal changes of the average temperature profiles (Figure 3) at a North Japan Pacific area $\left(42^{\circ} \mathrm{N}\right.$, "North" or "N") and a South Japan Pacific area ( $30^{\circ} \mathrm{N}$, "South" or "S") were cited from [19] with a slight modification. The profiles labeled "North" "will be explained later. From the figure we observe that there are large seasonal variations and the slopes are steep at depths shallower than $100 \mathrm{~m}$ and that there are large differences between the sea areas. 


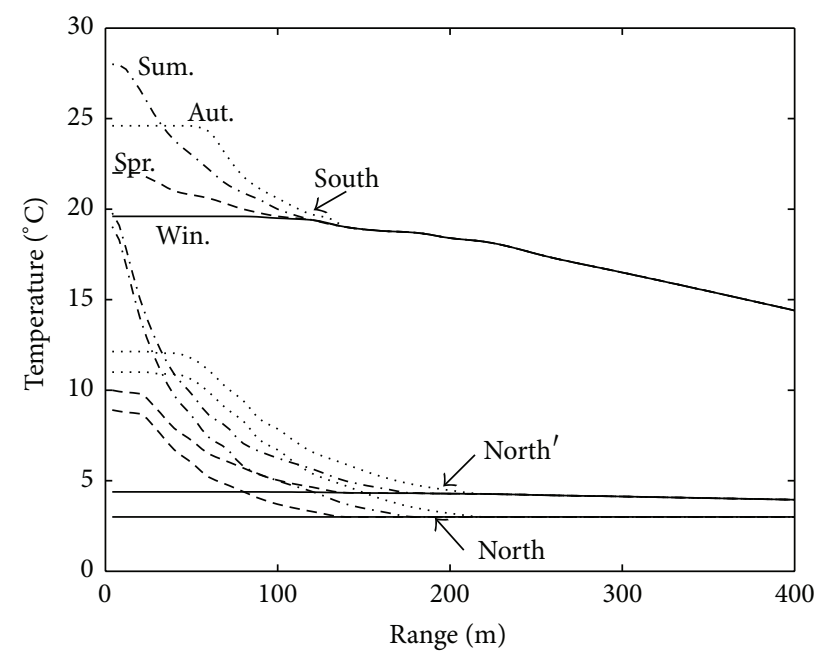

Figure 3: Sea temperature profiles for "North" $\left(42^{\circ} \mathrm{N}\right)$, "North" $\left(41^{\circ} \mathrm{N}\right)$, and "South" $\left(30^{\circ} \mathrm{N}\right)$ in the Pacific Ocean near Japan. Original profiles in [19] were slightly modified. North' profiles are simulated by the interpolation of North and South profiles.

The absorption attenuation is calculated by

$$
A(r)=2 \int_{0}^{r} \alpha\left(r^{\prime}\right) d r^{\prime}
$$

It is a common practice in using a QES that we give a constant $\alpha$ for each frequency and try to remove this range dependence of the attenuation. Actually, however, $\alpha$ is not a constant but changes especially for the water temperature as shown in Figure 2 and expressed, in our analysis, as

$$
\begin{aligned}
& \alpha(r ; f, \text { Area, Season }) \\
& \text { Area }=\left\{S, N^{\prime}, N\right\}, \text { Season }=\{\text { Win, Spr, Sum, Aut }\},
\end{aligned}
$$

where Area and Season are expressed by self-evident approximate labels.

The difference in latitudes of South and North in Figure 3 is $12^{\circ}$ and is too large for our common practice. So that, we simulate a more real situation by interpolation and make profiles at $41^{\circ} \mathrm{N}$ (call "North" or " $\mathrm{N}^{\prime \prime}$ "), that is, $1^{\circ}$ or 60 nautical miles further south than North. Simulating our actual practice of $\alpha$ setting, we use, as a medium constant value, the $\alpha$ value at $50 \mathrm{~m}$ in spring. Using $\mathrm{N}^{\prime}$ profiles, the attenuation variations at $\mathrm{N}^{\prime}$ from the fixed characteristics at $\mathrm{N}$ at six frequencies

$$
\begin{aligned}
& \Delta A\left(r ; f, \mathrm{~N}^{\prime}, \text { Season }\right)=2 \int_{0}^{r} \alpha\left(r^{\prime} ; f, \mathrm{~N}^{\prime}, \text { Season }\right) d r^{\prime} \\
& -2 r \alpha(50 \mathrm{~m} ; f, \mathrm{~N}, \mathrm{Spr})
\end{aligned}
$$

are calculated.

Moreover, let us consider the error caused by using a fixed value of $\alpha$, assuming that a more suitable temperature profile was given. The difference of the absorption attenuation estimates for North and Spring, using the temperature profile and the fixed average absorption coefficient, is

$$
\begin{aligned}
\Delta A\left(r ; r_{m}, f, \mathrm{~N}, \mathrm{Spr}\right)= & 2 \int_{0}^{r} \alpha\left(r^{\prime} ; f, \mathrm{~N}, \mathrm{Spr}\right) d r^{\prime}-2 r \\
& \cdot \frac{1}{r_{m}} \int_{0}^{r_{m}} \alpha\left(r^{\prime} ; f, \mathrm{~N}, \mathrm{Spr}\right) d r^{\prime},
\end{aligned}
$$

where the averaging is performed from 0 to $r_{m}$. Although averaging might be performed with weights considering target distribution [20], the simple method is adopted here.

\section{Results and Discussion}

3.1. Universal Diagrams of Echosounder Performance. Figure 4 shows the universal diagram for the single echo case obtained by (10) and (12); the regions where SNR $>20 \mathrm{~dB}$, $\Theta>7^{\circ}$, and $a<16 \mathrm{~cm}$ are shaded as roughly appropriate regions. The SNR border of $20 \mathrm{~dB}$ is selected such that the noise effect can be ignored. According to (10) and (12), the SNR curves change $+18 \mathrm{~dB}$ /octave for $a$ and $-18 \mathrm{~dB} /$ octave for $\Theta$, and at low frequencies approximately $-12 \mathrm{~dB} /$ octave for $r$ due to the spreading attenuation. The frequency ranges of the roughly appropriate regions are $17-400 \mathrm{kHz}$ for $r=100 \mathrm{~m}$, but it shrinks to $20-80 \mathrm{kHz}$ for $r=200 \mathrm{~m}$. It will be convenient to show rough maximum ranges as a function of frequency as Figure 5 (the line labeled " $\alpha$ error" will be explained later).

Figure 6 shows the frequency-SNR curves obtained by (16) for the multiple echo case in a fashion similar to that of Figure 4. The roughly appropriate region is shaded as in Figure 4, but the lower bound of $\Theta$ is set at $28^{\circ}$ in order to keep the bearing resolution angle not too large. Differing from the single echo case, the SNR dependence on $a$ is $12 \mathrm{~dB}$ /octave, the dependence on $\Theta$ is $-12 \mathrm{~dB} /$ octave, the dependence on $r$ is relaxed, and the roughly appropriate region exists even for $400 \mathrm{~m}$ at near $40 \mathrm{kHz}$, although the decreasing characteristics of SNR at high frequencies become somewhat severe.

Furusawa [2] used the cavitation threshold, which increases at high frequencies, for the power density $w$ instead of the present constant $w$. By the present modification, along with the slight modification for noise expression, (1), the SNR expression has become more appropriate for quantitative purposes and the frequency dependence has become simple and can be clearly understood. With the present modification the SNR becomes low and its deterioration becomes severe at high frequencies, but there is no large difference between the two methods at low frequencies. By the present improvement, the interpretation of the expressions and graphs becomes easy. The constant- $a$ SNR curves of (10) increase at low frequencies as a function of $f^{6}$ and decrease sharply at high frequencies with the increase of absorption attenuation; therefore, peaks of the maximum SNR appear and they shift to a lower frequency with the increase of $r$. The frequency characteristics of the constant- $\Theta$ curves of (12) are of the absorption attenuation itself, and they are roughly constant at low frequencies where the attenuation is small, but they deteriorate at high frequencies and at large ranges. 

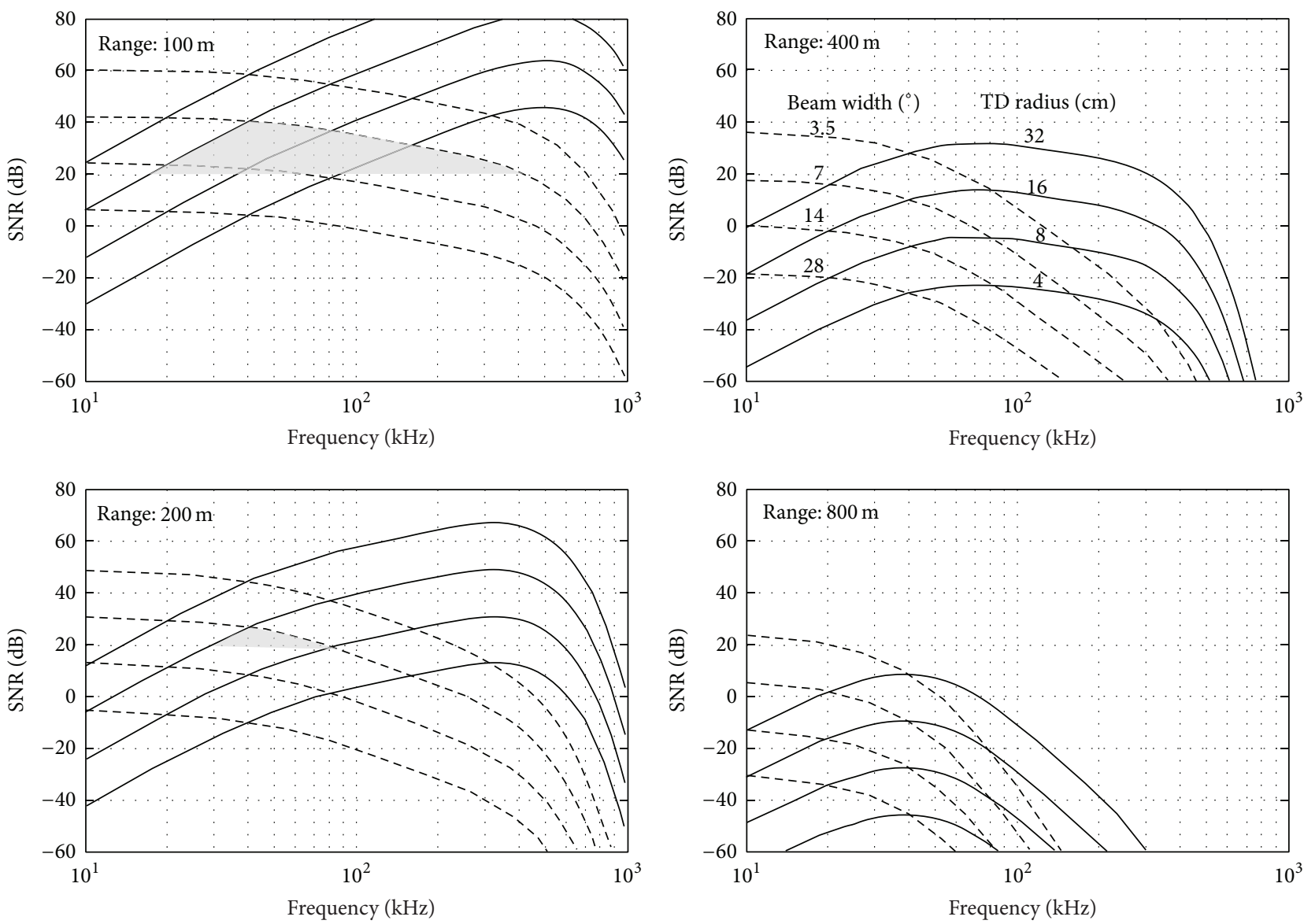

FIGURE 4: Universal diagram of echosounder performance for single fish echoes. The SNR for a single fish echo (TS $=-40 \mathrm{~dB}$ ) is plotted as a function of frequency for parameters of range, $r$, transducer radius, $a$, and beam width, $\Theta$, as shown in the $400 \mathrm{~m}$ range panel. Roughly appropriate regions where $\mathrm{SNR}>20 \mathrm{~dB}, \Theta>7^{\circ}$, and $a<16 \mathrm{~cm}$ are shaded.

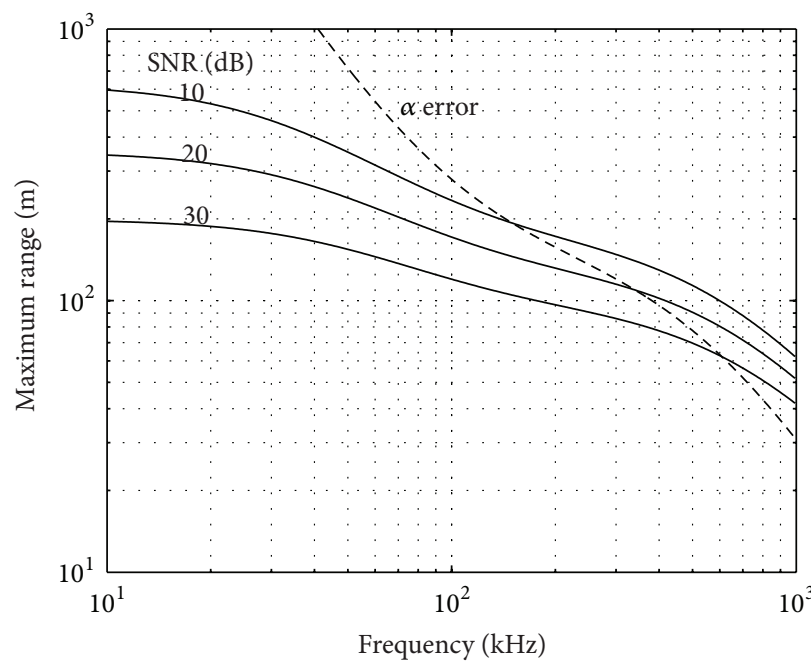

FIGURE 5: The range where the SNR for single fish echo is 10, 20, and $30 \mathrm{~dB}$ as an index of maximum measurable range. The line labeled " $\alpha$ error" is the range where absorption attenuation error is estimated to be $1 \mathrm{~dB}$. 

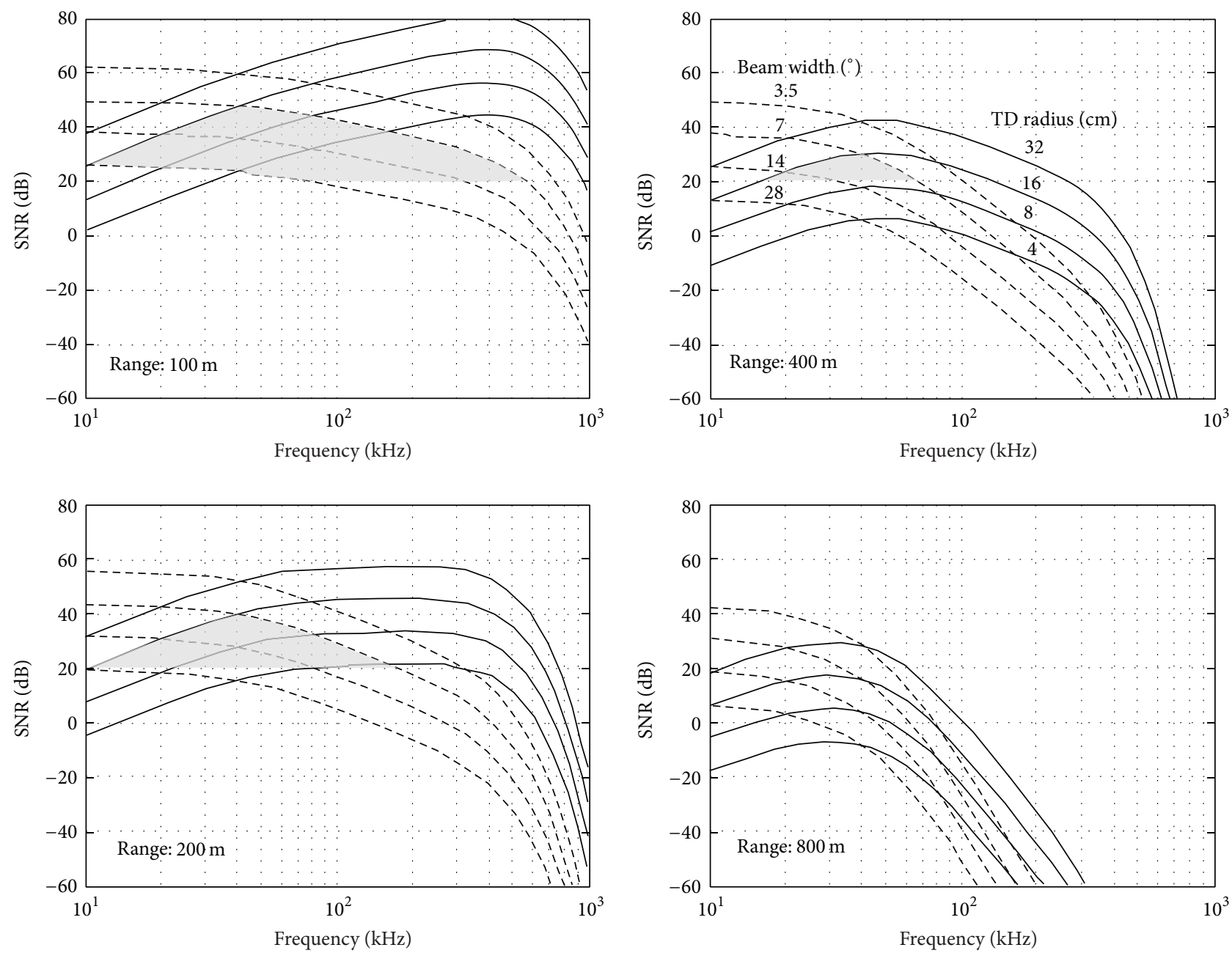

FiguRE 6: Universal diagram of echosounder performance for multiple echoes. The SNR for a multiple echo $\left(\mathrm{TS}=-40 \mathrm{~dB}, n=0.1 \mathrm{fish} / \mathrm{m}^{3}\right.$, and $S_{V}=-50 \mathrm{~dB}$ ) is plotted as a function of frequency for parameters of range, $r$, transducer radius, $a$, and beam width, $\Theta$, as shown in $400 \mathrm{~m}$ range panel. Roughly appropriate regions are shaded.

The values of adjustable parameters in (13) and (17) are approximate, and they are changeable to fit user's own sounder parameters. In such adjustment, it is sufficient only to shift the SNR scale. For example, if a vessel is more silent and $N V_{0}$ is $142 \mathrm{~dB}$, electric power density $w$ is $3 \mathrm{~W} / \mathrm{cm}^{2}$, and efficiency $\eta$ is 0.75 , then from the computation

$$
\begin{aligned}
& 10 \log \left(\frac{3}{2.5}\right)+10 \log \left(\frac{0.75}{0.6}\right)+(155-142) \\
& =14.8 \mathrm{~dB}
\end{aligned}
$$

the SNR increases by about $15 \mathrm{~dB}$, and the SNR scales in Figures 4 and 6 may be read adding by $15 \mathrm{~dB}$.

Figures 4 and 6 can be applied not only to QES but also to fisheries echosounders (FES). An FES operating at multiple frequencies usually uses a broader beam for a lower frequency and the low frequency is used to search a broader area and a high frequency is used to observe fish in high resolution. For example, let us compare the performance of an FES with a combination of $120 \mathrm{kHz}$ and $7^{\circ}$ beam and $38 \mathrm{kHz}$ and $28^{\circ}$ beam; as seen from Figure 4, the SNR for $120 \mathrm{kHz}$ is larger up to $400 \mathrm{~m}$ than $38 \mathrm{kHz}$. The beam widths of QES are usually selected to be the same at multiple frequencies, mainly for the purpose to observe frequency difference of scattering [3]; therefore, the SNR at a lower frequency is always higher. Common sense for FES, therefore, is not always true for QES and caution must be exercised.

The discussion in Section 2.1 suggests that we should consider mainly the self-vessel sailing noise in fish scattering measurements from a cruising vessel. In fact, Nishimura [8] observed the fact that received noise increased by about $20 \mathrm{~dB}$ when a ship started to move. Also, Korneliussen [21] observed propeller noise up to $30 \mathrm{~dB}$ higher than noise while drifting, especially in shallow waters and above dense and large fish schools. These facts are the simple result that we measure signals on the order of milliwatts near an engine with power on the order of megawatts [22]. If vessel noise is reduced by several countermeasures [23], a noise spectrum level can be considerably reduced as shown by the lower vessel noise line in Figure 1 [9], but the vessel self-noise is still generally larger than the wind-induced noise. Of course, in cases of a drifting ship, stopping a ship engine, using a suspended 


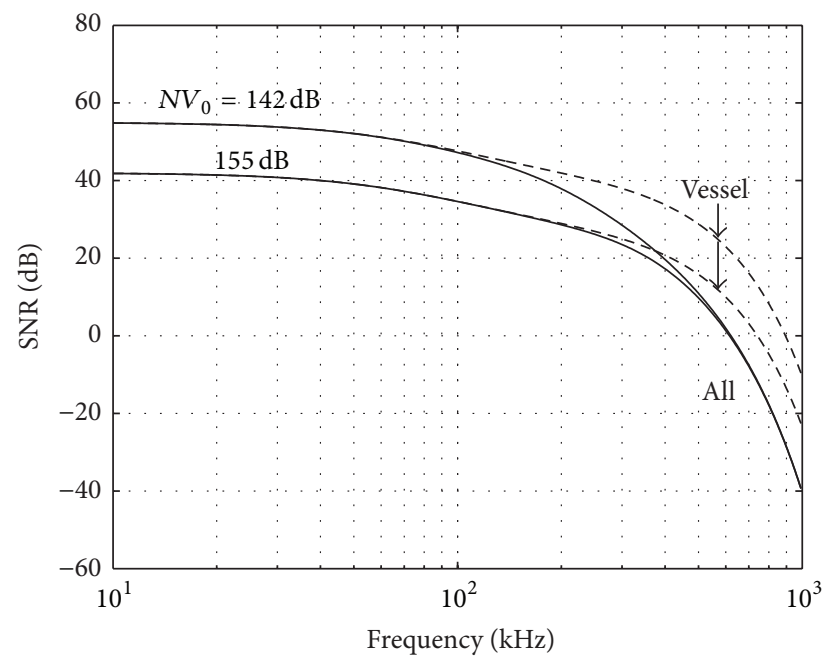

FIGURE 7: The effect of sea thermal noise and receiver noise on SNR for a target with $T S=-40 \mathrm{~dB}$ at $r=100 \mathrm{~m}$ and a beam width $7^{\circ}$. The SNR based on all noises (self-vessel, sea thermal, and receiver noises) is shown by the solid lines for two types of ship with $N V_{0}=$ $142 \mathrm{~dB}$ (noise reduced) and $155 \mathrm{~dB}$. The dashed curves indicate the SNR based only on the self-vessel noise; the lower dashed curve is the same as the corresponding curve in the upper left panel of Figure 4.

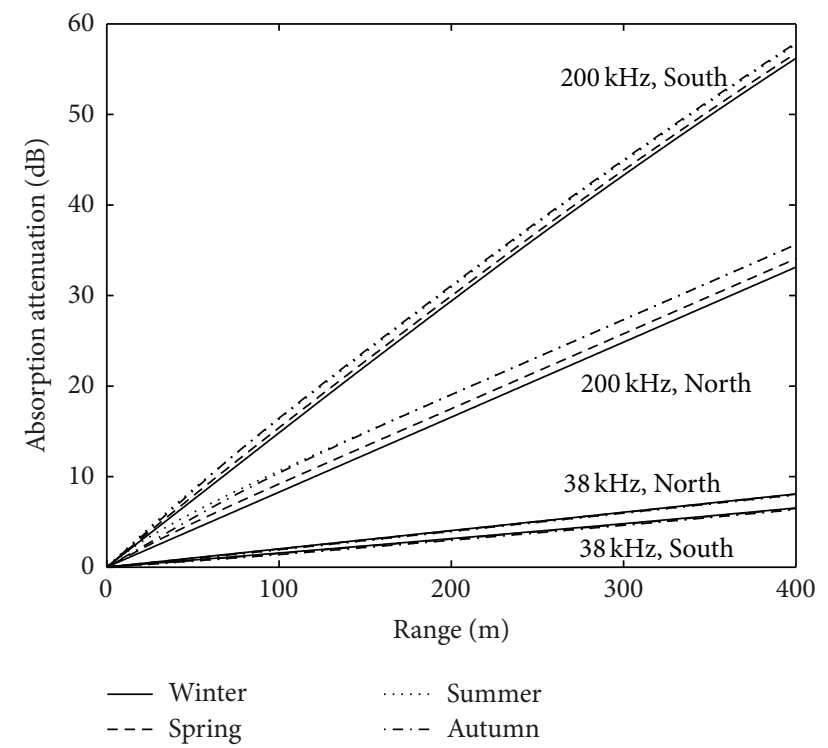

Figure 8: Absorption attenuation at $38 \mathrm{kHz}$ and $200 \mathrm{kHz}$ for North and South seas and four seasons computed by using the temperature profiles shown in Figure 3. Season difference is hardly discernible at $38 \mathrm{kHz}$ and also between Summer and Autumn at $200 \mathrm{kHz}$.

echosounder from a ship, measurement from a buoy, or using a stationary system, wind-induced noise will dominate; even in such cases, a modification of $N V_{0}$ will suffice to estimate the SNR using (10), (12), and (16).

3.2. SNR at Especially High Frequencies. At especially high frequencies, however, since the vessel self-noise and windinduced noise decrease, we may have a situation where the thermal noise and the receiver noise of QES itself are dominant. According to [24], the total noise power spectrum level including the thermal noise of seawater and hydrophone and the receiver noise is shown as

$$
N=N_{A}+\frac{N_{T}}{\eta}+N_{H}(F-1)
$$

where the first term represents ambient noise other than the sea thermal noise, the second term the thermal noise of the sea and hydrophone, and the third term the receiver noise, where $N_{H}$ is the value determined by hydrophone specifications, and $F$ is the noise figure of a preamplifier. The last term can be expressed as $N_{H 0} f^{2}$ taking out frequency dependence, and assuming $10 \log F=5 \mathrm{~dB}$ and typical hydrophone parameters, we have $10 \log N_{H 0}=-70 \mathrm{~dB}$ re $1 \mu \mathrm{Pa}^{2} \mathrm{~Hz}^{-3}$; this value is $5 \mathrm{~dB}$ larger than the case for the sea thermal noise (2). The SNR for a single echo is derived in a fashion similar to (12), but using the above noise characteristics and $N_{V}$ (1) in place of $N_{A}$ :

$$
\begin{aligned}
R_{F}= & 4 \times 0.51^{6} \pi^{4} c^{3} \rho \\
& \cdot \frac{\eta w D^{4} \sigma_{\mathrm{bs}}}{\Delta f\left[N_{V 0}+N_{T 0} f^{4} / \eta+N_{H 0} f^{4}\right]} \\
& \cdot \frac{1}{\Theta^{6} r^{4} 10^{0.2 \alpha(f) r}} .
\end{aligned}
$$

Figure 7 compares SNR calculated for the two vessel noises by this equation with the SNR for which only vessel self-noise is used as in Figure 4. As frequency increases the difference of the SNR for the two vessels becomes small mainly due to the contribution from the receiver noise, and the effect of this noise becomes prominent from $\sim 200 \mathrm{kHz}$ for the noisereduced vessel with $N V_{0}=142 \mathrm{~dB}$ and $\sim 400 \mathrm{kHz}$ for the vessel with $N V_{0}=155 \mathrm{~dB}$. To make the receiver noise small, we need a highly efficient transducer, an amplifier with a small noise figure, and appropriate matching between the amplifier and transducer.

3.3. Countermeasures for Noise. Noise removal methods have been reported in $[21,25,26]$. Reasonable correction should be possible when SNR is high as $>10 \mathrm{~dB}$, but correction might be difficult in a low SNR condition, when correction is especially needed. Therefore, it is important to build a measurement system, including a survey vessel, with high SNR (e.g., to select low frequencies), to conduct survey in good SNR conditions (e.g. lowering ship speed), and to select object fish (school) echoes in postprocessing (to make the ratio $\sum A_{E} / A_{C}$ in (4) large).

As described in Simrad EK60 Reference Manual [27], an effective way of monitoring SNR and knowing the maximum measurable range is to show an echogram of " $40 \log r$ " TVG output, whose minimum display level is the minimum TS value to be measured minus an expected SNR value, and to recognize the range where noise starts to appear as the maximum range. For example, if the minimum TS is $-60 \mathrm{~dB}$ and the expected SNR is $20 \mathrm{~dB}$, the minimum display level of TS should be $-60-20=-80 \mathrm{~dB}$. 

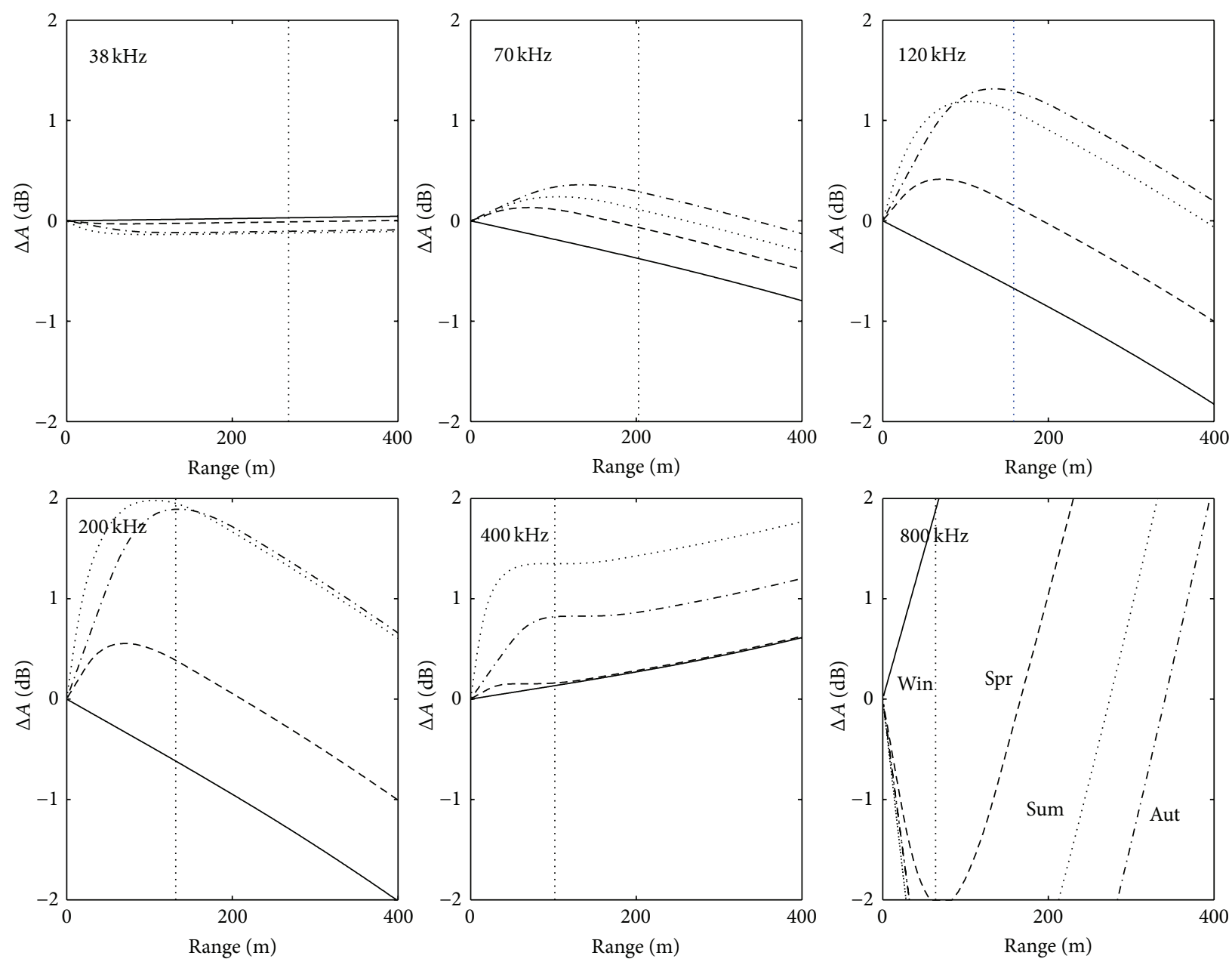

FIgURE 9: Deviations of two-way absorption attenuations $(\Delta A)$ at North' sea for six frequencies from the attenuation computed by using a fixed absorption coefficient of North, Spring, and $50 \mathrm{~m}$ depth. The line labels are shown in $800 \mathrm{kHz}$ panel. The dotted vertical lines are drawn at the rough maximum ranges with $20 \mathrm{~dB}$ SNR shown in Figure 4.

Higher frequencies up to about $800 \mathrm{kHz}$ are mainly used for fish species classification or discrimination between small animals and fish, and ordinarily resultant volume backscattering strengths are not directly used for abundance estimation; therefore, small errors may be admissible. The uppermost frequencies with which this paper deals are less than $1 \mathrm{MHz}$ and the main object is fish which are the targets of fisheries, and therefore the frequency characteristics of TS are roughly assumed to be flat. If our main objects were small animals such as zooplankton, the frequency characteristics of TS should also largely affect the SNR. Liu et al. [28] used a high-pass prolate-spheroid liquid model for TS and obtained universal diagrams as shown in Figure 4 but with another parameter of body size. The results demonstrate that the SNR becomes maximum around $1 \mathrm{MHz}$ for range $50 \mathrm{~m}$ and animal size $1-3 \mathrm{~mm}$.

3.4. Compensation Errors of Absorption Attenuation. First, let us see the synoptic characteristics of absorption attenuation. Figure 8 shows the absorption attenuation (18) at 38 and
$200 \mathrm{kHz}$ using the temperature profiles shown in Figure 3. We see that the attenuation is approximately one order of magnitude larger at $200 \mathrm{kHz}$ than at $38 \mathrm{kHz}$, that season difference is hardly discernible at $38 \mathrm{kHz}$ and also between Summer and Autumn at $200 \mathrm{kHz}$, that large difference exists between North and South at $200 \mathrm{kHz}$, and that the attenuation is larger at North than South at $38 \mathrm{kHz}$ but the inverse is true at $200 \mathrm{kHz}$; the last fact can be explained by Figure 2 which shows inversion of the temperature dependence at near $70 \mathrm{kHz}$. This figure simply suggests that the correction of the absorption must be made carefully to match environmental conditions especially for high frequencies.

Figure 9 shows the error $\Delta A(20)$ caused by using the fixed value of $\alpha$. Variations which are not negligible appear from $120 \mathrm{kHz}$, and at $400 \mathrm{kHz}$ the variations become somewhat smaller, but at $800 \mathrm{kHz}$ they become very large. The peculiar phenomenon at $400 \mathrm{kHz}$ can be explained by the characteristics shown in Figure 2. The curves for spring correspond to the case that there were only areal difference but no time difference in the temperature profiles; as expected, the variations are rather small. As a whole, the error may 

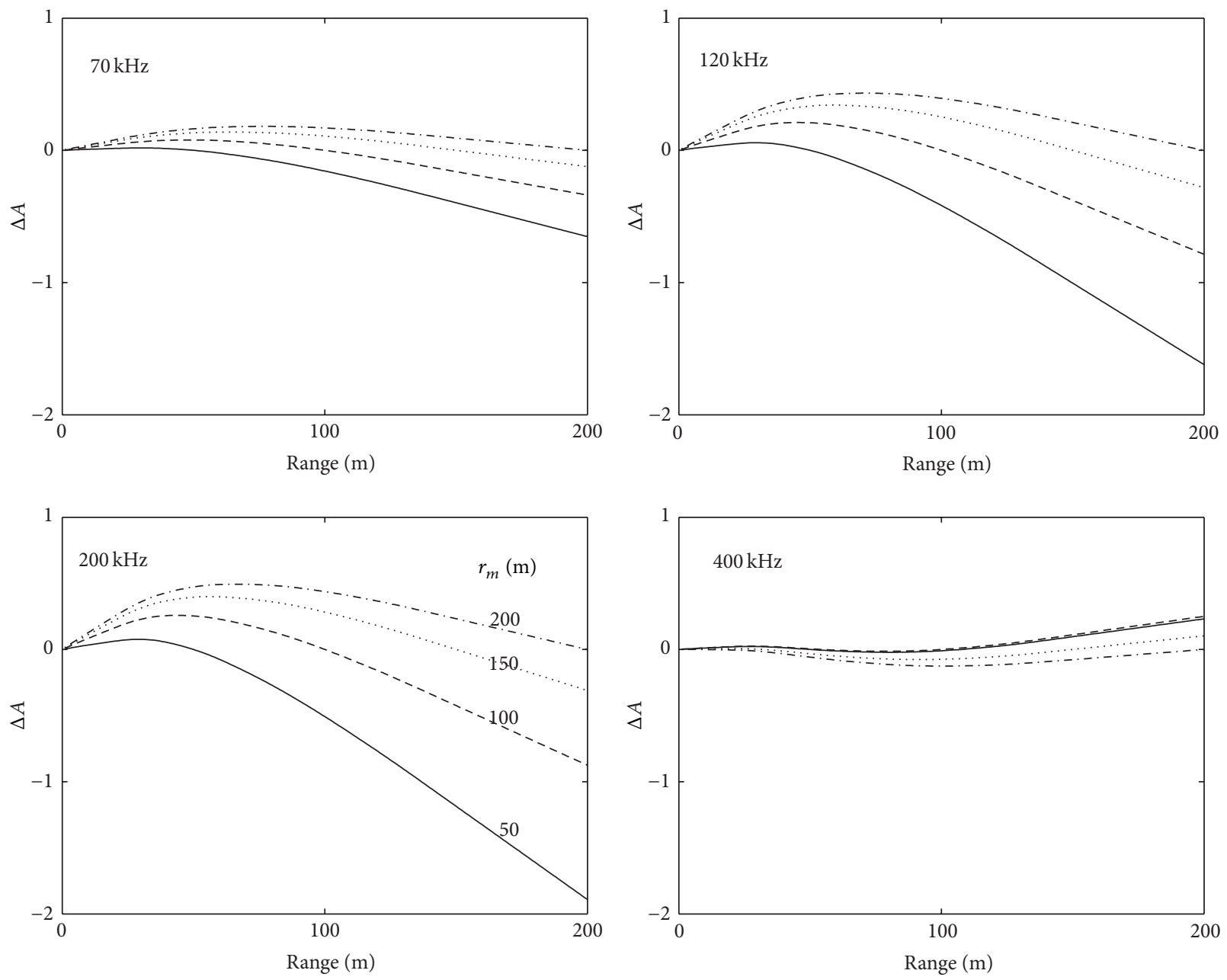

Figure 10: Deviations of two-way absorption attenuations $(\Delta A)$ by using fixed values of absorption coefficient averaged over range $r_{m}$. The profile used is of Spring at North shown in Figure 3.

be a few decibels at frequencies higher than $120 \mathrm{kHz}$, if the temperature profiles are not measured frequently and accurate absorption coefficients are not given.

Figure 10 indicates the errors for more appropriate correction (21). The result for $38 \mathrm{kHz}$ is very small and the result for $800 \mathrm{kHz}$ is too large and they are not shown. Again $400 \mathrm{kHz}$ shows surprisingly small error. The similar calculation for North and Autumn gave similar results and for Winter negligible error, but for Summer the error becomes considerably larger (not shown). South profiles gave similar characteristics. From these results, if we set an averaging range, $r_{m}$, properly for target fish, the error by using a fixed coefficient can be made small. However, caution must be paid to the fact that the above calculation assumed the exact temperature profiles which are not the case in actual practice. It seems better to set the averaging range, $r_{m}$, at approximately half of the target range, $r$. In place of using an average coefficient, a simpler alternative way is using a fixed coefficient at a medium depth as was adopted in the derivation of Figure 9.

The area, season, and method of correction adopted as above are only examples to show the degree of error; therefore, actual errors may be larger or smaller according to each method or custom of the user of a QES. To evaluate error, it is necessary that each user of QES compute variation in a similar fashion to match his/her QES, sea area, and survey method.

Since the expression of the absorption coefficient by Francois and Garrison $[17,18]$ so far used in this paper was derived through theory and many and diverse experimental data in various seas, its reliability seems to be high and their expression is appropriate for our fisheries acoustics application. But the degree of error claimed in their paper is around $5 \%$, and then there is the possibility to introduce error which is not negligible in attenuation compensation especially at high frequencies where $\alpha$ value is large. Ona et al. [29] pointed out that the difference of $\alpha$ values by the expression of Francois and Garrison and Fisher and Simmons [30] amounts to $4 \mathrm{~dB} / \mathrm{km}$ at $333 \mathrm{kHz}$, and this value is also about $5 \%$. The dashed line labeled " $\alpha$ error" in Figure 5 is the range, $r$, obtained from $2 \times 0.05 \times \alpha(f) r=1$ where $\alpha$ is calculated by Francois and Garrison's expression, that is, the range where $5 \%$ error of $\alpha$ gives $1 \mathrm{~dB}$ error. The range is $120 \mathrm{~m}$ at $300 \mathrm{kHz}$ and this range is nearly equal to 
the rough maximum range for $20 \mathrm{~dB} S \mathrm{NR}$. At higher frequencies, the $\alpha$ error becomes a stronger constraint than SNR. This problem is not easy to overcome, but a possible method is to check the absorption attenuation compensation by the TS measurement, by the split beam method, of standard targets suspended at different depths.

At the frequency regions around $70 \mathrm{kHz}$ and $400 \mathrm{kHz}$, where the temperature characteristics of $\alpha$ is reversed (Figure 2), the variation of $\alpha$ is comparatively small. The frequency of $70 \mathrm{kHz}$ is a good choice for QES next to $38 \mathrm{kHz}$ because of the above reason and also because a high SNR is possible (Figure 4). At $38 \mathrm{kHz}$, use of a fixed $\alpha$ value causes a very small error. These frequencies, therefore, provide a robust QES.

\section{Conclusions}

In order to obtain species identification information from the relative frequency response, the measurement error must be very small, for example, smaller than $0.5 \mathrm{~dB}$. The errors considered in this paper are added to the calibration error of $\sim 4 \%$ or $0.2 \mathrm{~dB}[3,31]$, and therefore they must be minimal.

Since error becomes large when SNR is small, it is necessary to know the limits of measurement conditions from the universal diagram as shown in Figure 4.

Serious error source at high frequencies is an inappropriate setting of the absorption coefficient. Frequent measurements of temperature profiles and adaptive setting of $\alpha$ are necessary. The best way is that we set an opportune temperature profile into an echosounder and it calculates an absorption coefficient profile to compensate for the absorption attenuation automatically.

Both the decrease of SNR and the error caused by absorption attenuation limit the maximum measureable range, and to increase the range is fundamentally difficult; therefore, a countermeasure is to reduce the range to the target fish using, for example, a suspension probe from a vessel $[32,33]$.

Since it is considerably difficult to accurately measure scattering of fish deeper than $200 \mathrm{~m}$ by a frequency above $100 \mathrm{kHz}$ with an error smaller than $1 \mathrm{~dB}$, we must be very careful in high frequency measurements of fish scattering.

\section{Conflict of Interests}

The author declares that there is no conflict of interests regarding the publication of this paper.

\section{Acknowledgments}

K. Sawada, National Research Institute of Fisheries Engineering, and K. Amakasu, Tokyo University of Marine Science and Technology, are thanked for their useful comments to the paper. The author would like to thank N. Williamson, Alaska Fisheries Science Center, NOAA, USA, for his valuable comments and correction of English. Anonymous referees are thanked for their helpful comments.

\section{References}

[1] J. Simmonds and D. MacLennan, Fisheries Acoustics: Theory and Practice, Blackwell, Oxford, UK, 2nd edition, 2005.

[2] M. Furusawa, "Designing quantitative echo sounders," The Journal of the Acoustical Society of America, vol. 90, no. 1, pp. 26-36, 1991.

[3] R. J. Korneliussen, N. Diner, E. Ona, L. Berger, and P. G. Fernandes, "Proposals for the collection of multifrequency acoustic data," ICES Journal of Marine Science, vol. 65, no. 6, pp. 982-994, 2008.

[4] A. M. Kaltenberg and K. J. Benoit-Bird, "Intra-patch clustering in mysid swarms revealed through multifrequency acoustics," ICES Journal of Marine Science, vol. 70, no. 4, pp. 883-891, 2013.

[5] D. Lemon, G. Borstad, L. Brown, and P. Johnston, "Moored multiple-frequency sonar for long-term continuous observations of zooplankton and fish," Journal of Marine Acoustics Society of Japan, vol. 40, no. 1, pp. 37-41, 2013.

[6] R. J. Korneliussen and E. Ona, "An operational system for processing and visualizing multi-frequency acoustic data," ICES Journal of Marine Science, vol. 59, no. 2, pp. 293-313, 2002.

[7] "The SIMFAMI project: species identification methods from acoustic multifrequency information," Final Report to the EC Q5RS-2001-02054, 2006.

[8] M. Nishimura, Study on the optimum frequency of echo sounders [Ph.D. thesis], Tohoku University, Sendai, Japan, 1969 (Japanese).

[9] Y. Takao, K. Sawada, Y. Miyanohana, T. Okumura, M. Furusawa, and D. Hwang, "Noise characteristics of Japanese fisheries' research vessels," The Journal of the Acoustical Society of America, vol. 103, no. 5, p. 3036, 1998.

[10] R. H. Mellen, "The thermal-noise limit in the detection of underwater acoustic signals," The Journal of the Acoustical Society of America, vol. 24, no. 5, pp. 478-480, 1952.

[11] H. Medwin and C. S. Clay, Fundamentals of Acoustical Oceanography, Academic Press, San Diego, Calif, USA, 1998.

[12] V. O. Knudsen, R. S. Alford, and J. W. Emling, "Underwater ambient noise," Journal of Marine Research, vol. 7, pp. 410-429, 1948.

[13] G. M. Wenz, "Acoustic ambient noise in the ocean: spectra and sources," The Journal of the Acoustical Society of America, vol. 34, no. 12, pp. 1936-1956, 1962.

[14] M. Furusawa, "Section and total scattering strengths of individual fish school," Journal of Marine Acoustics Society of Japan, vol. 38, no. 4, pp. 177-194, 2011.

[15] F. E. Tichy, H. Solli, and H. Klaveness, "Non-linear effects in a $200-\mathrm{kHz}$ sound beam and the consequences for target-strength measurement," ICES Journal of Marine Science, vol. 60, no. 3, pp. 571-574, 2003.

[16] A. Pedersen, Effects of nonlinear sound propagation in fisheries research [Doctoral thesis], University of Bergen, Bergen, Norway, 2006.

[17] R. E. Francois and G. R. Garrison, "Sound absorption based on ocean measurements. Part I: pure water and magnesium sulfate contributions," The Journal of the Acoustical Society of America, vol. 72, no. 3, pp. 896-907, 1982.

[18] R. E. Francois and G. R. Garrison, "Sound absorption based on ocean measurements. Part II: Boric acid contribution and equation for total absorption," Journal of the Acoustical Society of America, vol. 72, no. 6, pp. 1879-1890, 1982. 
[19] Marine Acoustics Society of Japan, Fundamentals and Applications of Marine Acoustics, Seizando, Tokyo, Japan, 2004 (Japanese).

[20] D. A. Demer, "An estimate of error for the CCAMLR 2000 survey estimate of krill biomass," Deep Sea Research Part II: Topical Studies in Oceanography, vol. 51, no. 12-13, pp. 1237-1251, 2004.

[21] R. J. Korneliussen, "Measurement and removal of echo integration noise," ICES Journal of Marine Science, vol. 57, no. 4, pp. 1204-1217, 2000.

[22] R. B. Mitson, "Ship noise related to fisheries research," Proceedings of the Institute of Acoustics, vol. 11, part 3, pp. 61-67, 1989.

[23] R. B. Mitson, Ed., Underwater Noise of Research Vessels: Review and Recommendations, ICES Cooperative Research Report, No. 209, ICES, Copenhagen, Denmark, 1995.

[24] J. W. Young, "Optimization of acoustic receiver noise performance," The Journal of the Acoustical Society of America, vol. 61, no. 6, pp. 1471-1476, 1977.

[25] J. L. Watkins and A. S. Brierley, "A post-processing technique to remove background noise from echo integration data," ICES Journal of Marine Science, vol. 53, no. 2, pp. 339-344, 1996.

[26] A. De Robertis and I. Higginbottom, "A post-processing technique to estimate the signal-to-noise ratio and remove echosounder background noise," ICES Journal of Marine Science, vol. 64, no. 6, pp. 1282-1291, 2007.

[27] A. S. Kongsberg Maritime, Simrad EK60 Reference Manual, 2012.

[28] X. Liu, M. Furusawa, E. Hamada, and C. Aoyama, “Designing acoustic transmitting-receiving system for volume backscattering measurement of zooplankton," Fisheries Science, vol. 65, no. 3, pp. 410-419, 1999.

[29] E. Ona, G. Macaulay, R. Korneliussen, and D. Chu, “The acoustic absorption coefficient at $333 \mathrm{kHz}$," Report, Working Group on Fisheries Acoustics, Science and Technology (WGFAST), Brest, France, 2012.

[30] F. H. Fisher and V. P. Simmons, "Sound absorption in sea water," The Journal of the Acoustical Society of America, vol. 62, no. 3, pp. 558-564, 1977.

[31] K. G. Foote, H. P. Knudsen, G. Vestnes, D. N. MacLennan, and E. J. Simmonds, "Calibration of acoustic instruments for fish density estimation: a practical guide," ICES Cooperative Research Report 144, ICES, Copenhagen, Denmark, 1987.

[32] E. Ona, "An expanded target-strength relationship for herring," ICES Journal of Marine Science, vol. 60, no. 3, pp. 493-499, 2003.

[33] K. Sawada, H. Takahashi, K. Abe, T. Ichii, K. Watanabe, and Y. Takao, "Target-strength, length, and tilt-angle measurements of Pacific saury (Cololabis saira) and Japanese anchovy (Engraulis japonicus) using an acoustic-optical system," ICES Journal of Marine Science, vol. 66, no. 6, pp. 1212-1218, 2009. 

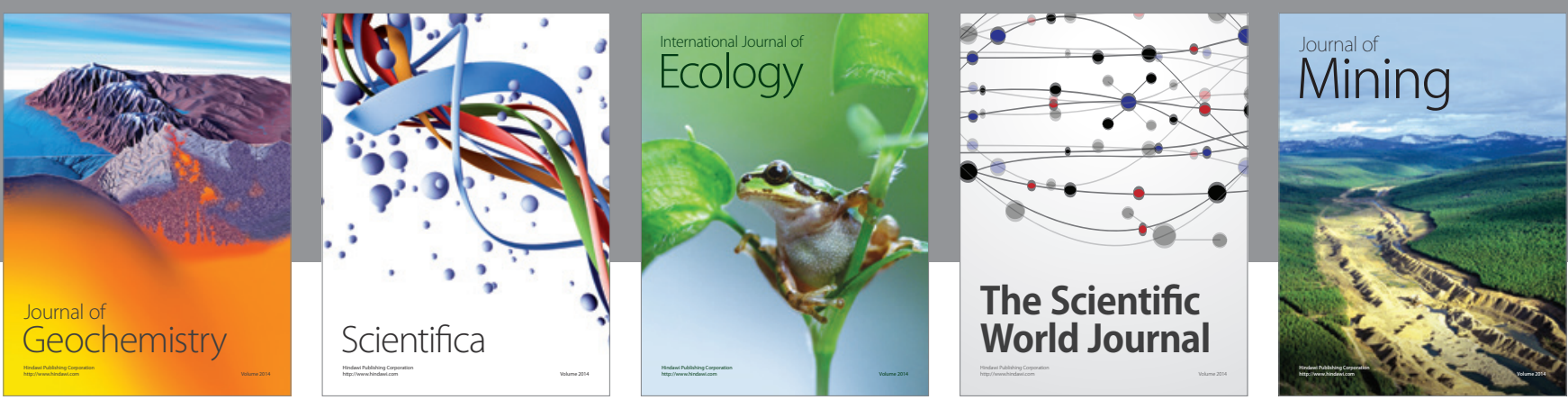

The Scientific World Journal
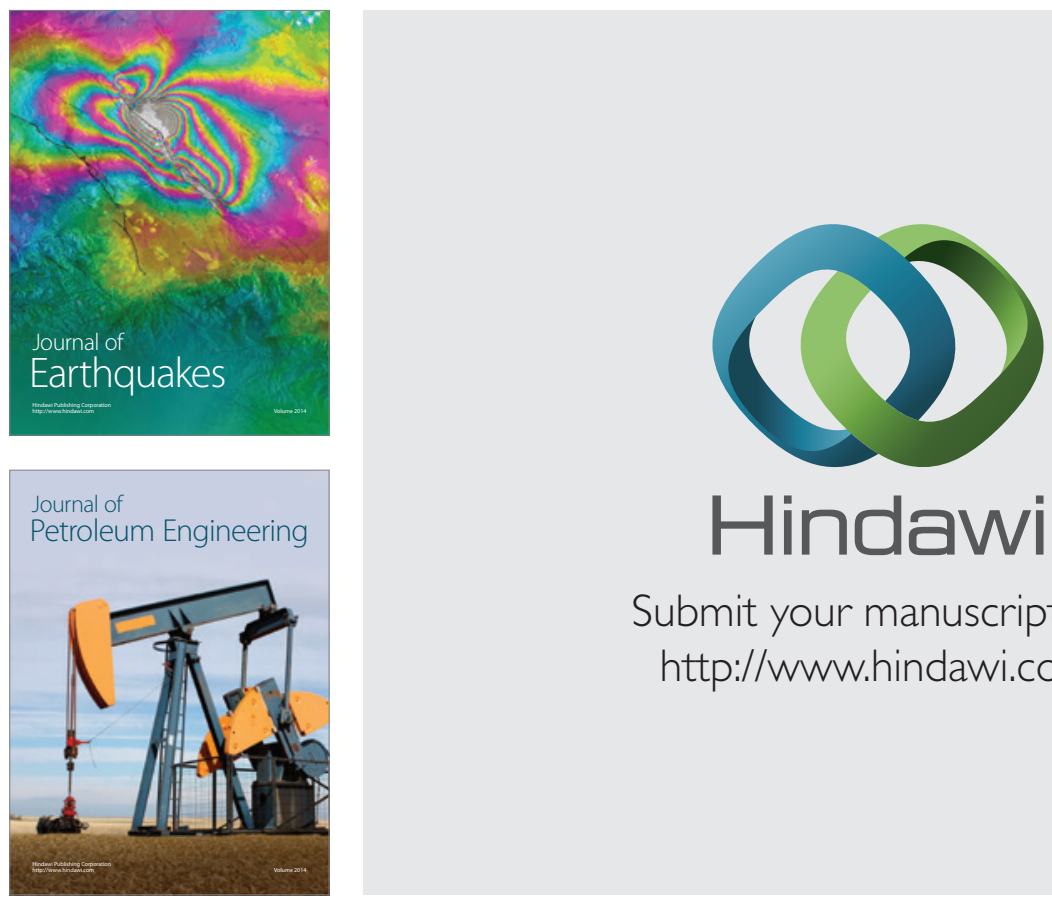

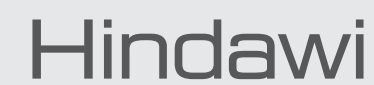

Submit your manuscripts at

http://www.hindawi.com
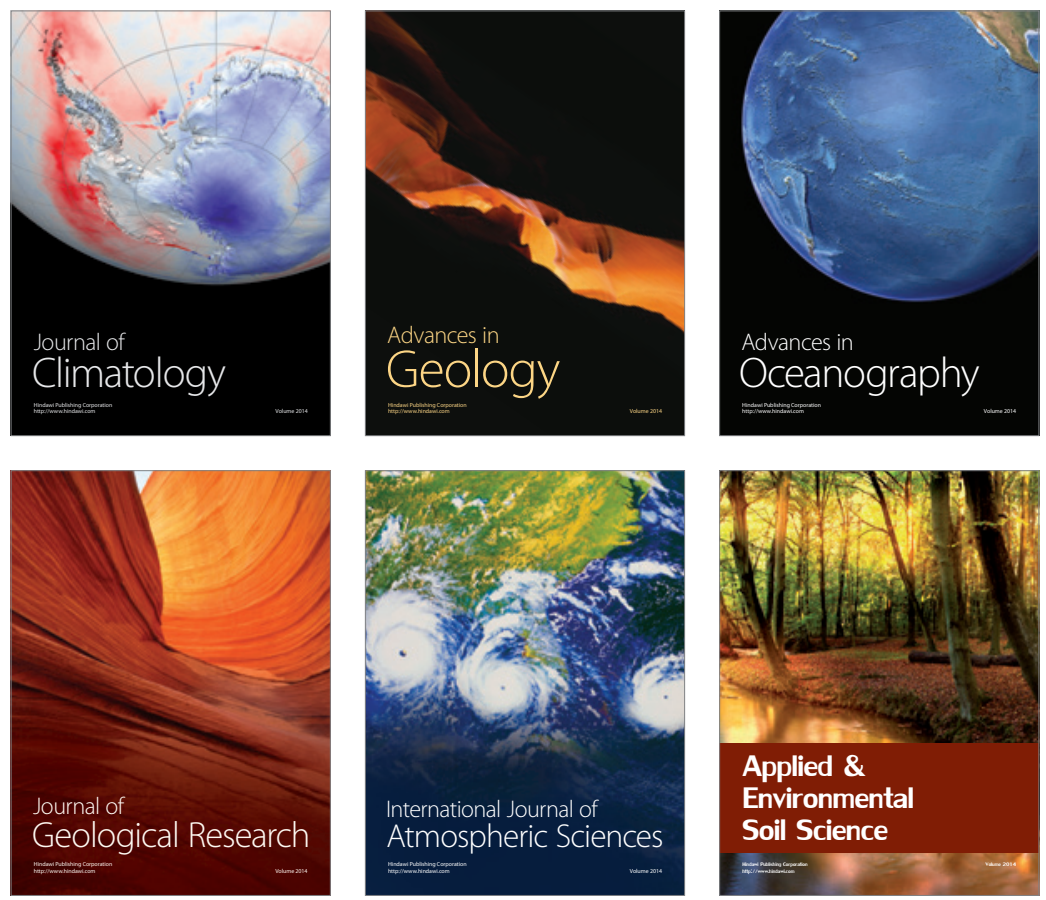
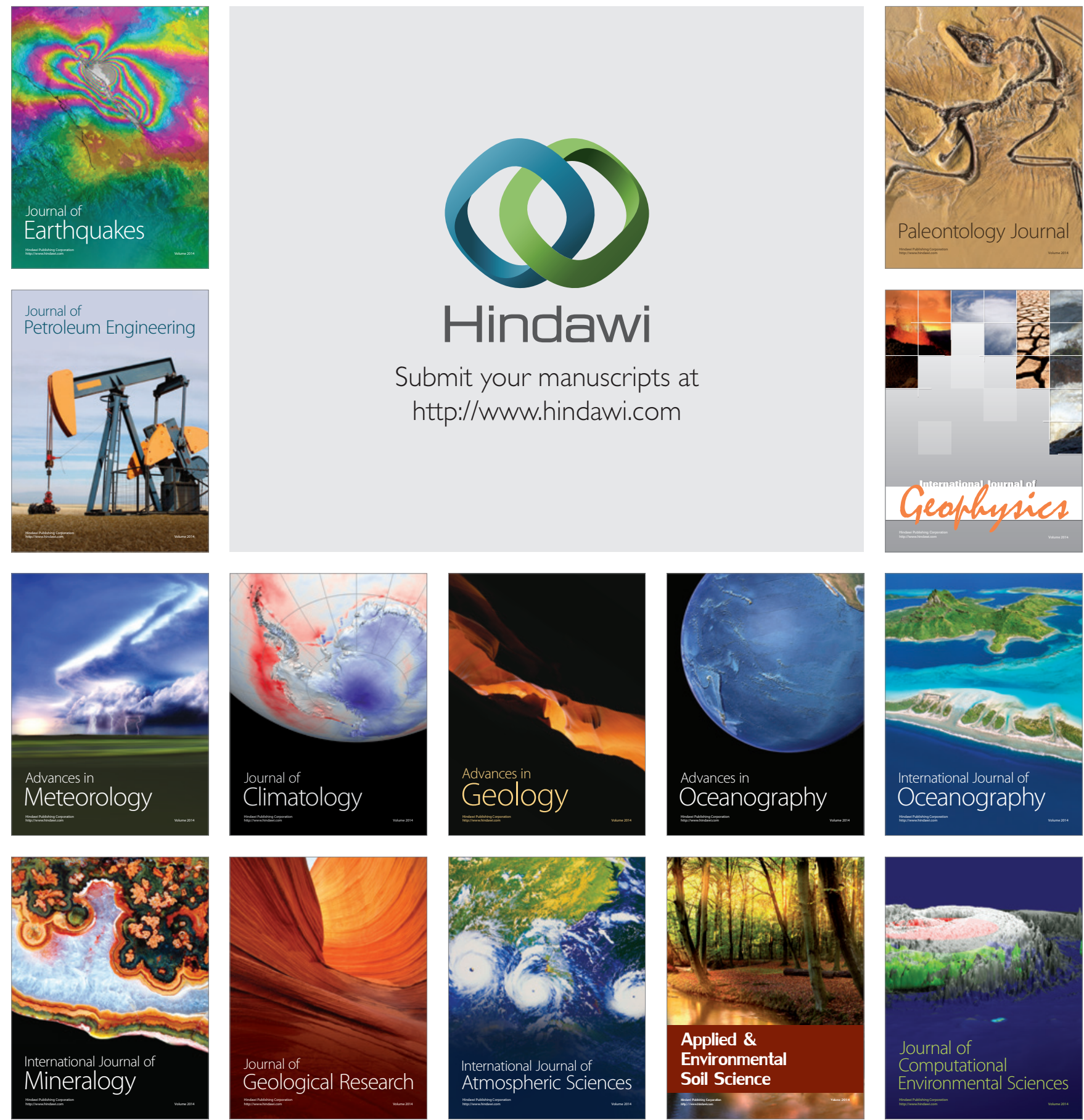